\title{
Biomechanics of the Sacroiliac Joint: Anatomy, Function, Biomechanics, Sexual Dimorphism, and Causes of Pain
}

\author{
ALI KIAPOUR, PHD, ${ }^{1,2}$ AMIN JOUKAR, MS, ${ }^{1}$ HOSSEIN ELGAFY, MD, ${ }^{1}$ DENIZ U. ERBULUT, PHD, ${ }^{1}$ \\ ANAND K. AGARWAL, MD, ${ }^{1}$ VIJAY K. GOEL, PHD ${ }^{1}$ \\ ${ }^{I}$ Engineering Center for Orthopaedic Research Excellence (E-CORE), Departments of Bioengineering and Orthopaedics, The University of Toledo, Toledo, Ohio; \\ ${ }^{2}$ Department of Neurosurgery, Massachusetts General Hospital, Harvard Medical School, Boston, Massachusetts
}

\begin{abstract}
Background: The sacroiliac joints (SIJs), the largest axial joints in the body, sit in between the sacrum and pelvic bones on either side. They connect the spine to the pelvis and thus facilitate load transfer from the lumbar spine to the lower extremities. The majority of low back pain (LBP) is perceived to originate from the lumbar spine; however, another likely source of LBP that is mostly overlooked is the SIJ. This study (Parts I and II) aims to evaluate the clinical and biomechanical literature to understand the anatomy, biomechanics, sexual dimorphism, and causes and mechanics of pain of the SIJ leading to conservative and surgical treatment options using instrumentation. Part II concludes with the mechanics of the devices used in minimal surgical procedures for the SIJ.

Methods: A thorough review of the literature was performed to analyze studies related to normal SIJ mechanics, as well as the effects of sex and pain on SIJ mechanics.

Results: A total of 65 studies were selected related to anatomy, biomechanical function of the SIJ, and structures that surround the joints. These studies discussed the effects of various parameters, gender, and existence of common physiological disorders on the biomechanics of the SIJ.

Conclusions: The SIJ lies between the sacrum and the ilium and connects the spine to the pelvic bones. The SIJ transfers large bending moments and compression loads to lower extremities. However, the joint does not have as much stability of its own against the shear loads but resists shear due the tight wedging of the sacrum between hip bones on either side and the band of ligaments spanning the sacrum and the hip bones. Due to these, sacrum does not exhibit much motion with respect to the ilium. The SIJ range of motion in flexion-extension is about $3^{\circ}$, followed by axial rotation (about $1.5^{\circ}$ ), and lateral bending (about $0.8^{\circ}$ ). The sacrum of the female pelvis is wider, more uneven, less curved, and more backward tilted, compared to the male sacrum. Moreover, women exhibit higher mobility, stresses/loads, and pelvis ligament strains compared to male SIJs. Sacroiliac pain can be due to, but not limited to, hypo- or hypermobility, extraneous compression or shearing forces, micro- or macro-fractures, soft tissue injury, inflammation, pregnancy, adjacent segment disease, leg length discrepancy, and prior lumbar fusion. These effects are well discussed in this review. This review leads to Part II, in which the literature on mechanics of the treatment options is reviewed and synthesized.
\end{abstract}

Biomechanics

Keywords: sacroiliac joint, anatomy, biomechanics, sexual dimorphism, causes of pain, surgery

\section{BACKGROUND}

One of the most overlooked sources of low back pain (LBP) is the sacroiliac joint (SIJ) due to its complex nature and the fact that presumed radicular pain syndromes could be linked to the SIJ. ${ }^{1}$ The SIJ is the largest axial joint in the body that connects the spine to the pelvis and thus transfers load between the lumbar spine and the lower extremities., ${ }^{2,3}$ However, the joint does not have as much stability against the shear loads. There are several ligaments across the joint that support and limit the movement of the SIJ. The tight wedging of the sacrum between the hip bones and the band of ligaments surround- ing the SIJs provide resistance to shear loads. Several of the largest and most powerful muscles of the body also surround the SIJ; however, these muscles don't produce its active movements.

The sacrum can move with respect to the ilium in 6 degrees of freedom, although this motion is minimal, and the joint's hyper- or hypo-mobility may cause pain emanating from the joint region. Sexual dimorphism exists in the pelvis. Men tend to have a relatively long and narrow pelvis, with a longer and more conical pelvic cavity than that of women. ${ }^{4}$ These sex differences also reflect in the biomechanics of the joint: the female SIJ has higher 


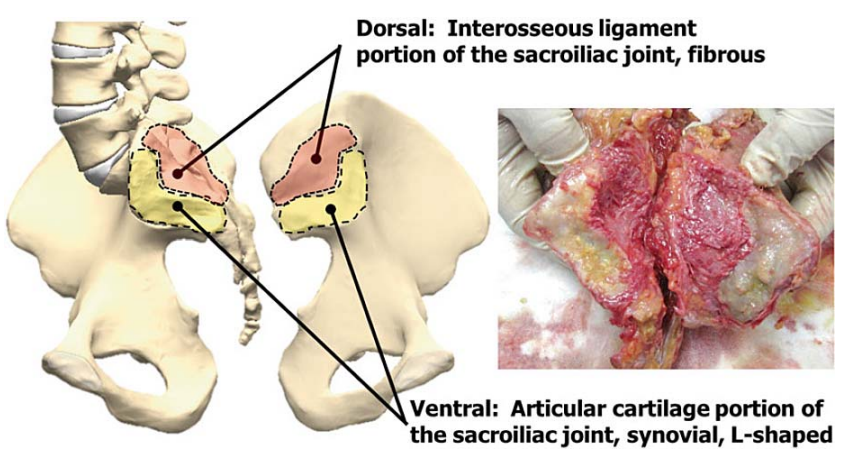

Figure 1. Articular surfaces of the sacroiliac joint. ${ }^{10}$

mobility, and more stresses, loads, and pelvisligament strains, compared to the male SIJ. ${ }^{5}$

Recent studies have reported a higher prevalence of LBP due to the SIJ, with some reports having estimated that the SIJ is the actual source of pain in $15 \%$ to $30 \%$ of cases. ${ }^{6-8}$ From an anatomical perspective, pathologic changes and injuries specific to different SIJ structures can result in SIJ pain. These changes or disorders include, but are not limited to, capsular and ligamentous tension, hypoor hypermobility, extraneous compression or shearing forces, micro- or macro-fractures, soft tissue injury, and inflammation. ${ }^{2}$

Due to the high importance of the SIJ to LBP, this Part I review addresses basic anatomy, function, biomechanics, and mechanisms of pain in the SIJ. The review leads to the need for treatment options and thus Part II narrates the mechanics of treatment options specific to SIJ.

\section{ANATOMY}

The SIJ, the largest axial joint in the body, connects the spine to the pelvis, which allows load transfer between the lumbar spine and the lower extremities. $^{2,3}$ The SIJ lies between the sacrum and the ilium, spanning about 1 to $2 \mathrm{~mm}$ in width and a joint on either side of the sacrum is held together by a fibrous capsule (Figures 1 and 2).

The sacral side of the joint is covered with hyaline cartilage that is thicker $(1.18 \mathrm{~mm})$ than iliac cartilage $(0.8 \mathrm{~mm})$, which appears more fibrocartilaginous. ${ }^{9}$ The iliac cortical bone is thicker than the sacral cortical bone $(0.36 \mathrm{~mm}$ vs. $0.23 \mathrm{~mm})$. Thus, cartilage and cortical bone thicknesses have a reverse relationship. No relationship between age and cortical bone thickness was observed by Dall et al. ${ }^{10}$ Regarding bone density, iliac cancellous bone density was greater than sacral bone in all anterior, central, and posterior parts of the joint.

\section{Ligaments}

Several ligaments depicted in Figure 2 support and limit the movement of the SIJ (see 7, Figure 2). These ligaments include the interosseous sacroiliac ligament (8), the posterior and anterior ligaments (5 and 6), and the sacrotuberous (4), sacrospinous (3) and iliolumbar ligaments ( 1 and 2 ). The interosseous ligament (8), also known as the axial ligament, connects the sacrum and ilium at the S1 and S2 levels. The long posterior sacroiliac ligament (5) is quite strong and consists of multiple bundles that pass from the lateral crest of the sacrum to the posterior superior iliac spine and the posterior end of the iliac crest. The anterior sacroiliac ligament (6) is a thin ligament. It is weaker than the posterior ligament and runs over the joint obliquely from sacrum to ilium. The sacrotuberous ligament (4) is located at the inferior-posterior part of the pelvis
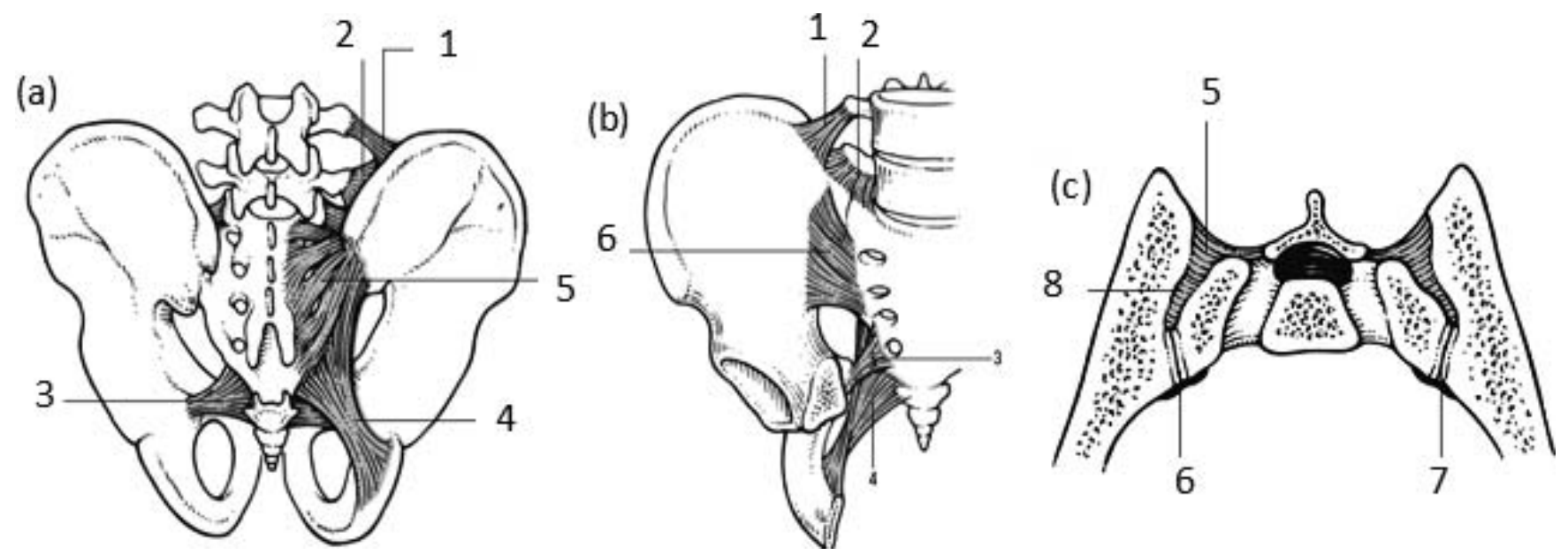

Figure 2. (a) Posterior view, (b) anterior view and (c) sacroiliac joint cut in transverse plane. 1, 2: superior and inferior iliolumbar ligaments, respectively; 3: sacrospinous ligament; 4: sacrotuberous ligament; 5: posterior sacroiliac ligaments; 6 : anterior sacroiliac ligaments; 7 : sacroiliac joint; 8 : interosseous ligament. ${ }^{11}$ 
Table 1. Sacroiliac joint (SIJ) ligaments, locations, and functions. ${ }^{10}$

\begin{tabular}{llc}
\hline Ligament & \multicolumn{1}{c}{ Location } & Primary Restraint \\
\hline $\begin{array}{l}\text { Posterior ligaments (5) } \\
\text { Long ligament }\end{array}$ & Posterior superior iliac spine to sacral tubercles & Sacral extension \\
$\quad$ Short ligament & & Sacral flexion \\
Sacrotuberous (4) & Posterior superior iliac spine and sacrum to ischial tuberosity & Sacral flexion \\
Sacrospinous (3) & Apex of the sacrum to ischial spine & Sacral flexion, axial rotation \\
Anterior ligament (6) & Crosses ventral and caudal aspect of SIJ & Sacral flexion, axial rotation \\
Interosseous (8) & Between sacrum and ilium dorsal to SIJ & Lateral side bending \\
Iliolumbar (1 and 2) & Transverse process of L5 to the iliac tuberosity and crest & Ventral band \\
Ventral band & & Forward flexion \\
Dorsal band & & Dorsal band \\
Sacroiliac part & & \\
\hline
\end{tabular}

and runs from sacrum to the ischial tuberosity. The sacrospinous ligament's (3) attachment is behind that of the sacrotuberous ligament, and it connects the outer edge of the sacrum and coccyx to the ischia of the ilium. The iliolumbar ligament (1 and 2) originates from the tip of the fifth lumbar vertebral body to the iliac crest. ${ }^{11}$ The long posterior sacroiliac ligament (5) can stretch in periods of reduced lumbar lordosis, such as during pregnancy. Table 1 summarizes sacroiliac joint ligaments, locations, and functions.

\section{Muscles}

While no muscles are designed to act on the SIJ to produce active movements, the joint is still surrounded by some of the largest and most powerful muscles of the body. These muscles include the erector spinae, psoas, quadratus lumborum, piriformis, abdominal obliques, gluteals, hamstrings, and pelvic floor muscles (levator ani and coccygeus muscles). While they do not act directly on the SIJ, the muscles that cross the joint act on the hip or the lumbar spine. ${ }^{12,13}$ Movements of the SIJ are indirectly produced by gravity and muscles acting on the trunk and lower limbs rather than active movements of the sacrum. ${ }^{11}$ However, pelvic floor muscles (levator ani and coccygeus muscles) act to stabilize the joints. Table 2 summarizes sacroiliac joint muscles, their actions, and their effect on SIJ.

\section{Summary}

The SIJ, the largest axial joint in the body, lies between the sacrum and the ilium and connects the spine to the pelvis. It allows load transfer from the lumbar spine to the lower extremities. The iliac side of SIJ has thinner cartilage, thicker cortical bone, and greater cancellous bone density than the sacral side. There are several ligaments and pelvic floor muscles (levator ani and coccygeus muscles) across the joint that support and limit the movement and mobility of the SIJ and helps in transmitting shear forces. The SIJ is surrounded by some of the largest and most powerful muscles of the body; however, these muscles are not designed to produce active movements.

Table 2. Sacroiliac joint (SIJ) muscles, actions, and effect on SIJ. ${ }^{10}$

\begin{tabular}{|c|c|c|}
\hline Muscle & Primary Action & Effect on SIJ \\
\hline Erector spinae & $\begin{array}{l}\text { Bilateral: back extension } \\
\text { Unilateral: side bending }\end{array}$ & Hydraulic amplifier effect \\
\hline \multicolumn{3}{|l|}{$\begin{array}{l}\text { Iliocostalis lumborum } \\
\text { Longissimus thoracis }\end{array}$} \\
\hline Multifidus & Back extension, side bending, rotation & $\begin{array}{l}\text { Imparts sacral flexion, force closure of SIJ with } \\
\text { deep abdominals }\end{array}$ \\
\hline Gluteus maximus & Hip extension, hip lateral rotation & Stabilizes SIJ \\
\hline Piriformis & Hip lateral rotation & $\begin{array}{l}\text { May alter SIJ motion via direct attachment to } \\
\text { the ventral aspect of the sacrum }\end{array}$ \\
\hline Biceps femoris & Hip extension, knee flexion & $\begin{array}{l}\text { Long head: Imparts sacral extension via } \\
\text { attachment to the sacrotuberous ligament }\end{array}$ \\
\hline $\begin{array}{l}\text { Deep abdominals } \\
\quad \text { Transversus abdominis }\end{array}$ & Compression of abdominal cavity & Forces closure of SIJ \\
\hline Iliacus & $\begin{array}{l}\text { Hip flexion (open chain) and tilts pelvis/ } \\
\text { sacrum ventrally (closed chain) }\end{array}$ & $\begin{array}{l}\text { Synchronous tilting of the pelvis and sacrum } \\
\text { ventrally (closed chain) }\end{array}$ \\
\hline $\begin{array}{l}\text { Pelvic floor } \\
\text { Levator ani } \\
\text { Coccygeus }\end{array}$ & Support pelvic viscera & Imparts sacral extension \\
\hline
\end{tabular}



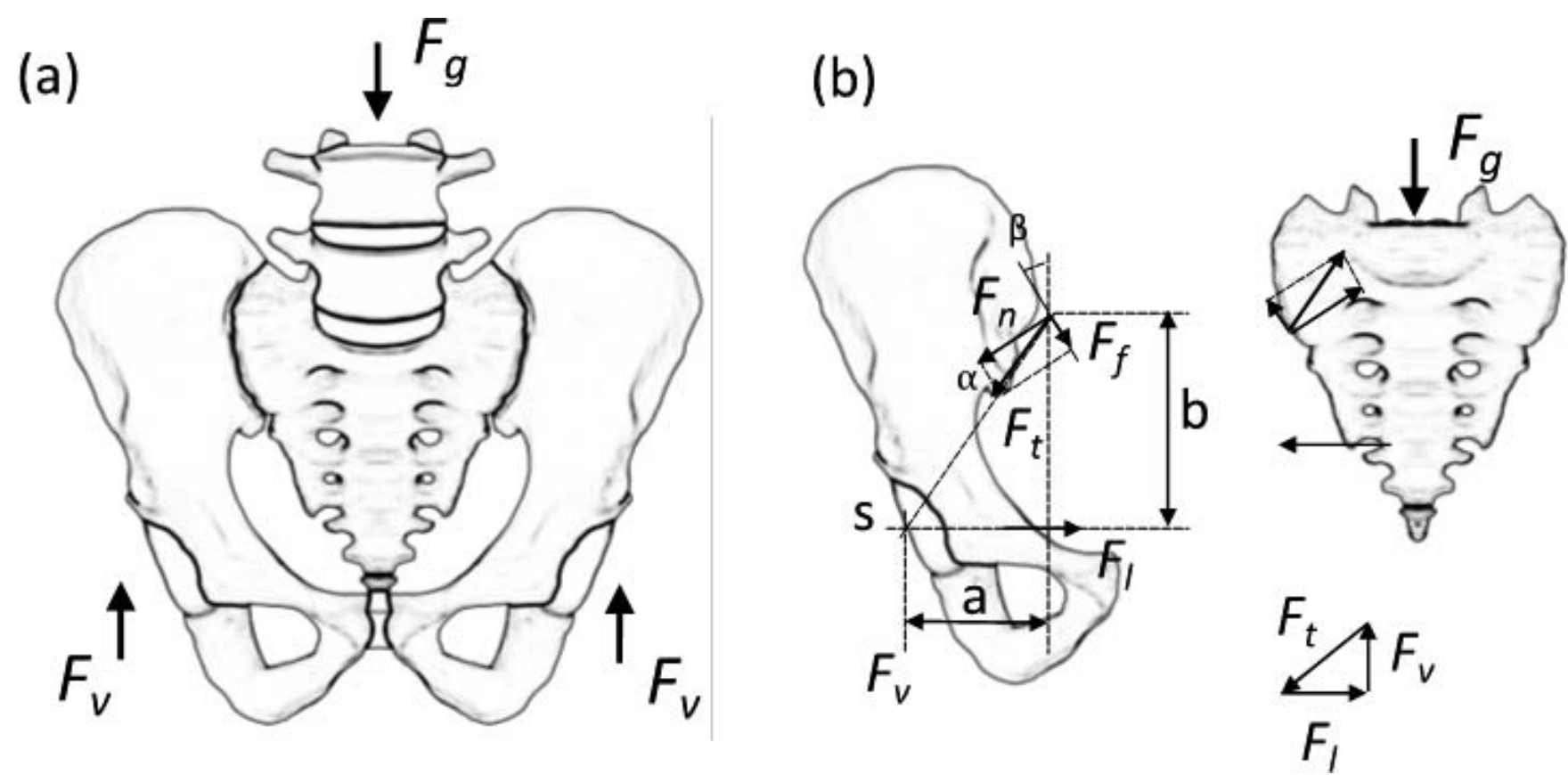

Figure 3. (a) Pelvis free-body diagram due to gravity. Trunk weight $\left(F_{g}\right)$ and hip joint forces $\left(F_{v}\right)$. (b) Free-body diagram of the self-bracing effect of the sacroiliac joint. Sacroiliac joint reaction force: normal $\left(F_{n}\right)$ and tangential $\left(F_{f}\right)$, ligament or muscle force $\left(F_{1}\right)$, and hip joint force $\left(F_{v}\right){ }^{14}$

\section{FUNCTION AND BIOMECHANICS}

The relatively flat shape of the SIJ along with its ligaments transfers large bending moments and compression loads; however, the joint does not have as much stability against shear loads. The selfbracing mechanism consists of forces produced by muscles and ligaments, which are normal to the joint surface and loading mode of the pelvis. (This, in turn, increases compression across the SIJ and thus helps in resisting shear loads.) Figures $3 \mathrm{a}$ and $3 \mathrm{~b}$ show the loading mode of the pelvis due to gravity and the free-body diagram of the selfbracing mechanism that involves normal and tangential forces of the joint surface, hip joint force, and muscle or ligament force, respectively. The friction coefficient of the SIJ surfaces is about 0.4 without grooves and ridges. Grooves and ridges allow additional resistance to protect the joint against shearing. ${ }^{14}$ It was shown that the transversus abdominis and the pelvic floor muscles (levator ani and coccygeus muscles) play a major role in SIJ stability as they increase the compression load across the SIJ to resist shear loads. ${ }^{15}$

Goudzward et $\mathrm{al}^{16}$ conducted a study on 12 human cadavers to assess the effect of the iliolumbar ligament on SIJ stability. Four different cases were tested: intact iliolumbar ligament, random dissection of iliolumbar ligament, further dissection of iliolumbar ligament, and a complete cut of the iliolumbar ligament. The rotations in the sagittal plane in response to various moments applied to the pelvis were determined. The sacral and iliac bones were fixed to the table, and a traction device to generate a tension in a string applied different moments. Eight light-reflecting markers helped to calculate the rotations in response to applied loads. The ventral side of the iliolumbar ligament decreased SIJ stability in the sagittal plane. The dorsal side and sacroiliac parts of the IL did not play significant roles in providing SIJ stability ${ }^{16}$. However, preserving the iliolumbar ligament would help to stabilize the L5-to-sacrum segment. ${ }^{17}$

The posterior sacroiliac ligaments contribute most to SIJ mobility, while the anterior sacroiliac ligament has little influence. ${ }^{18}$ The motion of the ilium with respect to the sacrum is known as nutation and counternutation, which equate to anterior sacral tilt and posterior sacral tilt, respectively. The sacrotuberous and sacrospinous ligaments resist nutation, while the long dorsal ligaments resist counternutation of the joint. ${ }^{19}$ During pregnancy, with increased laxity of SIJ ligaments, the pain is mostly experienced in long dorsal ligament due to its counteraction to the counternutation. ${ }^{20}$ Men also experience pain in this region due to its superficial location, which puts asymmetric stress on the SIJ. Although not 
desirable, flattening of lumbar lordosis brings about a decrease in SIJ nutation. ${ }^{21}$

A cadaveric study was done by Wang et $\mathrm{al}^{22}$ to calculate SIJ motion and the influence of anterior and posterior ligaments on SIJ stability. Four female specimens were subjected to 5 different magnitudes of eccentric compressive loads (a combination of compression, bending moment, and forward shear due to inclination angle) through the sacrum. The main motions of the sacrum were lateral rotation and nutation, which were less than $1.2^{\circ}$. Transverse portions of anterior sacroiliac ligament and posterior sacroiliac ligament resist lateral rotation. Also, nutation is prevented by the superior portion of the anterior and lower portion of posterior ligaments (ie, shear-resisting couple). Dissection of these 2 ligaments had a significant influence on joint stability, which decreased. Interosseous ligaments were the strongest ligaments, but their contributions to the joint's translations were quite small.

Hammer et $\mathrm{al}^{23}$ predicted that SIJ cartilage and ligaments play a significant role in pelvic stability. An increase in SIJ cartilage and interosseous ligament, iliolumbar ligament, anterior sacroiliac ligament, and posterior sacroiliac ligament stiffness values led to a decrease in the pelvic motion with highest strains at the interosseous ligament. Pubic ligaments had the least effect on the pelvic motion. These ligaments contributed to transferring loads horizontally at the acetabulum and ilium. In contrast, increasing stiffness of sacrospinous and sacrotuberous ligaments had the opposite effect, leading to an increase in the pelvic motion. They also facilitated vertical load transfer followed by sacrum translation. Moreover, in a standing position, the ligaments' strains were higher than in sitting position.

Eichenseer et $\mathrm{al}^{20}$ also evaluated the correlation between ligament stiffness and SIJ stress and motion. They showed that by decreasing ligaments' stiffness, stress and motion at the SIJ would increase. Moreover, interosseous ligaments had the highest strains under different spine motions, confirming the findings of Hammer et al.

Dujardin et $\mathrm{al}^{24}$ assessed the SIJ micromotion under a compression load applied at the ischial tuberosity. Sectioning of the sacrospinous and sacrotuberous ligaments decreased SIJ stability. Buyruk et al, ${ }^{25}$ using Doppler imaging of vibrations, showed that left and right SIJ stiffness value are different under various loading conditions. These findings suggest that there is asymmetry in the SIJ stiffness, and it may lead to the low back and pelvic pain. Rothkotter et $\mathrm{al}^{26}$ indicated that the SIJ ligamentous structure failed at $3368 \mathrm{~N}$ under transverse loading, and the corresponding displacement ranged from 5.5 to $6.6 \mathrm{~mm}$. They reported that the self-bracing mechanism of the SIJ worked better under dorso-cranial loading than other loading directions.

\section{Summary}

The SIJ transfers large bending moments and compression loads to lower extremities; however, the joint per se does not have as much stability against the shear loads. Wedging of the sacrum and the ligaments' band afford the resistance to shear loads. Grooves and ridges allow additional resistance to protect the joint against shearing. It is shown that ventral side of the iliolumbar ligament, posterior sacroiliac ligaments, interosseous ligaments, and sacrotuberous and sacrospinous ligaments play a major role in SIJ stability, whereas pubic ligaments and anterior sacroiliac ligaments and dorsal side of iliolumbar ligaments have least effect on pelvic stability.

\section{RANGE OF MOTION}

The sacrum can move with respect to the ilium in all directions, although motion magnitudes are minimal (Figure 4). The lumbosacral pivot point is the intersection of the middle osteo-ligamentous column and the lumbosacral intervertebral disc. Placing instrumentation posterior and extending anteriorly of this pivot would provide rotational stability. ${ }^{4}$

While the primary function of the SIJ is to absorb and transmit forces from the spine to the pelvis, the joint is also responsible for facilitating parturition and limiting rotation around the medio-lateral axis. ${ }^{2,3}$ The SIJ is unique such that it is rather stable, and the motion of the joint is minimal. ${ }^{9}$ The magnitude of the range of motion (ROM) of the SIJ has been debated and studied extensively. The SIJ motion has been evaluated using different techniques, such as roentgen stereophotogrammetric, radiostereometric, ultrasound, and Doppler techniques. ${ }^{28,29}$ The SIJ rotations in different planes and translations along axes do not exceed ${ }^{\circ}$ to $3^{\circ}$ and 2 $\mathrm{mm}$, respectively., ${ }^{9,30}$ The joint's ROM in flexionextension is about $3^{\circ}$. Axial rotation of the SIJ is 
$\mathbf{a}$

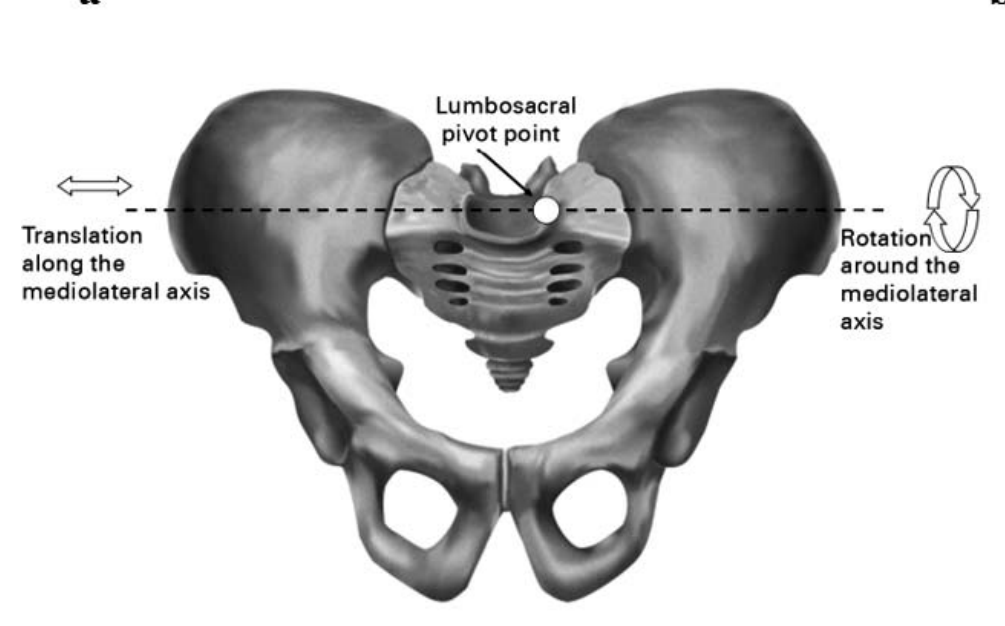

b

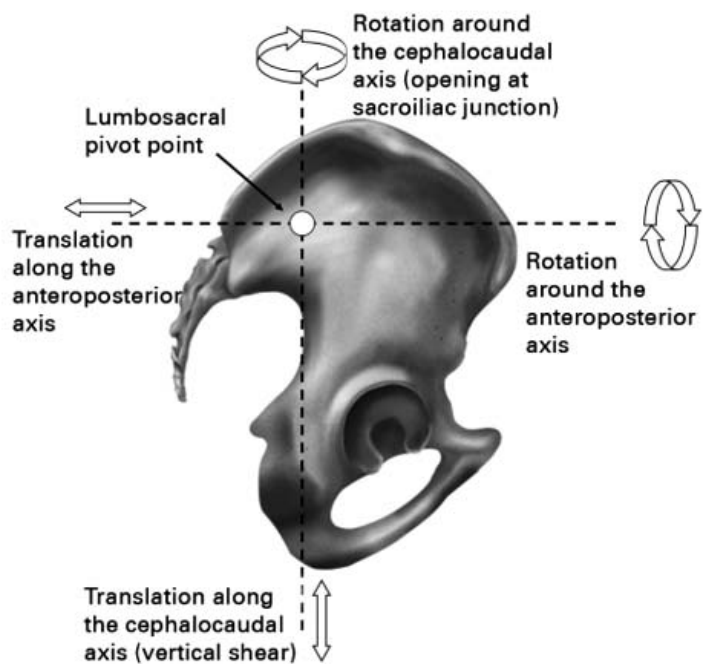

Figure 4. Pelvis 6 degrees of movement and lumbosacral pivot point, (a) coronal plane, (b) sagittal plane. ${ }^{27}$

about $1.5^{\circ}$, and lateral bending is about $0.8^{\circ} .{ }^{12}$ As the characteristics of the SIJ change with age, these values undergo changes. ${ }^{31,32} \mathrm{~A}$ series of cadaveric studies by Vleeming et $\mathrm{al}^{33,34}$ reported that flexion and extension rarely exceeded $2^{\circ}$, with an upper limit of $4^{\circ}$. Brunner et $\mathrm{al}^{35}$ reported that the maximum ROM, based on cadaver data, for men and women was $1.2^{\circ}$ and $2.8^{\circ}$, respectively. Another study, by Sturesson et al, ${ }^{28}$ involved measuring SIJ movements in 25 patients diagnosed with SIJ pain. All movements were incredibly small with translations never exceeding $1.6 \mathrm{~mm}$ and an upper limit of $3^{\circ}$ in rotations. This study also found that no differences in ROM between symptomatic and asymptomatic SIJs, which led the authors to conclude that 3-dimensional motion analysis is not a useful tool for identifying painful SIJs in most patients. ${ }^{28}$ Jacob et $^{2}{ }^{36}$ reported mobility of SIJs of 15 healthy people using 3-dimensional stereophotogrammetric technique. The average total rotation and translation were $1.7^{\circ}$ and $0.7 \mathrm{~mm}$, respectively. Finally, in an attempt to understand the load-displacement behavior of single and paired SIJs, Miller et $\mathrm{al}^{12}$ quantified rotations about all 3 axes for one and both ilia fixed, and with static test loads applied in the superior, lateral, anterior, and posterior directions. Movements in all planes with one leg fixed ranged between 2 and 7.8 times those measured with both legs fixed.

\section{Summary}

The sacrum can move with respect to the ilium in 6 degrees of freedom, although this motion is minimal. It is shown that the SIJ ROM is greatest in flexion-extension (about $3^{\circ}$ ), followed by axial rotation (about $1.5^{\circ}$ ), and lateral bendings (about $0.8^{\circ}$ ). The male and female SIJ ROM values are also different with the maximum ROM of $1.2^{\circ}$ degrees (men) and $2.8^{\circ}$ (women). Moreover, the average translation of the joint is about $0.7 \mathrm{~mm}$ and seldom exceeds $2 \mathrm{~mm}$. In addition, the motion of the SIJ while standing on one leg is higher than when standing on both legs.

\section{SEXUAL DIMORPHISM}

Sexual dimorphism exists in the pelvis with the male pelvis being larger, a distinction that decreases in the later years of childhood. While the sacral base articular facet for the fifth lumbar vertebra occupies more than a third of the width of the sacral base in men, it occupies less than a third in women. Compared to the male sacrum, the female sacrum is wider, more uneven, less curved, and more backward tilted. Men tend to have a relatively long and narrow pelvis, with a longer and more conical pelvic cavity than that of women (Figure 5; Table 3). Women have a wider sciatic notch, and their acetabula are wider apart than those of men. In the second decade of life, women develop a groove in the iliac bone, the paraglenoidal sulcus, which usually does not occur in men. Such sex-related differences in the development of the SIJ can lead to a higher rate of SIJ misalignment in young women. ${ }^{21}$

Female sacral cartilage $(1.92 \mathrm{~mm})$ is thicker than male $(1.71 \mathrm{~mm})$; however, they are not significantly 

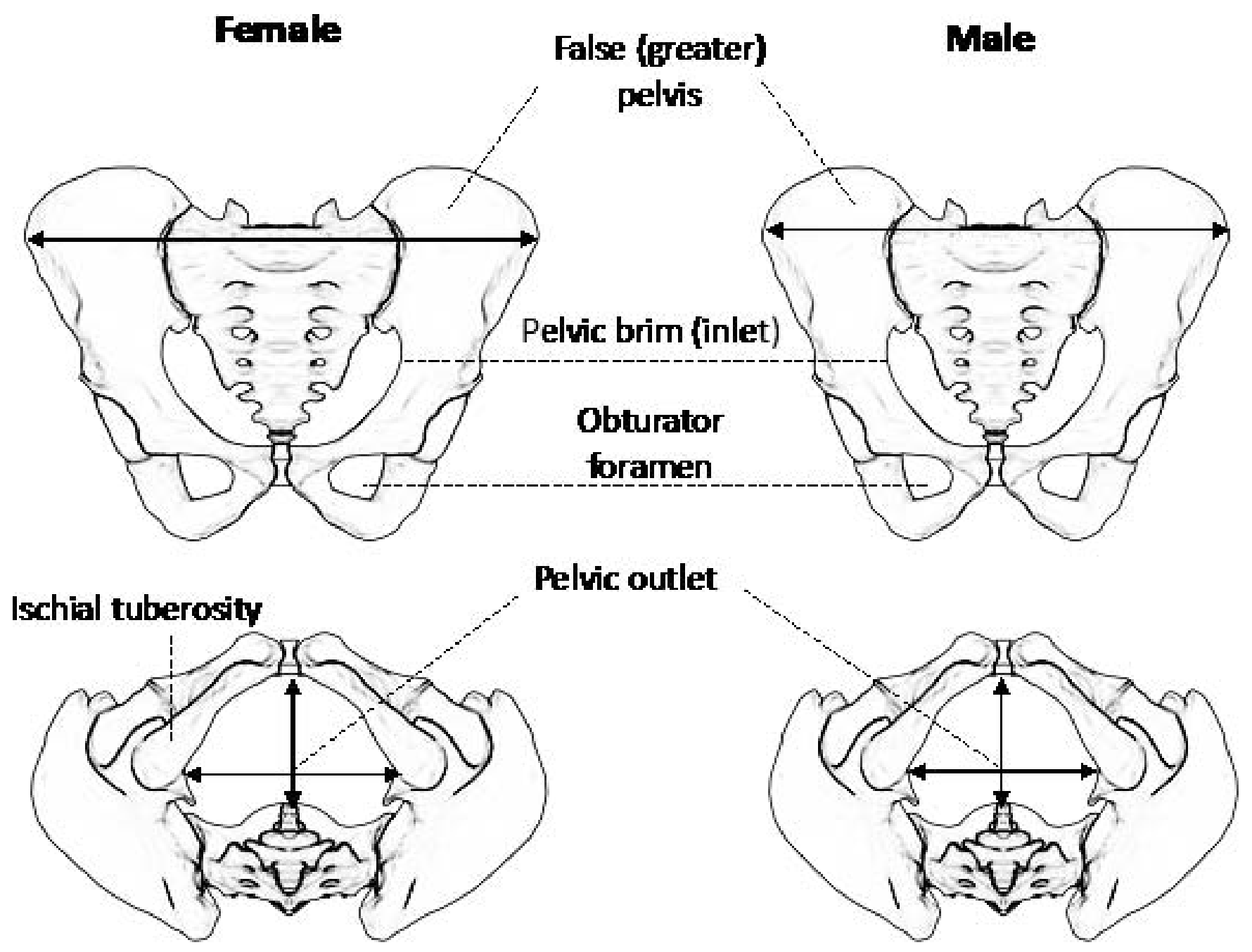

Iferio visw

Figure 5. Comparison of the female and male pelvis: (top) brim (inlet) and (bottom) pelvic outlet. ${ }^{37}$

different. Moreover, female iliac cortical bone is thinner than male iliac cortical bone. ${ }^{12}$

According to a study by Ebraheim and Biyani, ${ }^{38}$ the SIJ surface area is relatively greater in adult men

Table 3. A biomechanical comparison of the female and male sacroiliac joint $(\mathrm{SIJ}){ }^{37}$

\begin{tabular}{|c|c|c|}
\hline Biomechanical Aspects & Female & Male \\
\hline SIJ motions & More rotational & More translational \\
\hline Angular range of motions & Higher (Up to $2.8^{\circ}$ ) & Lower (Up to $1.2^{\circ}$ ) \\
\hline Sacral cartilage & Thicker & Thinner \\
\hline Iliac bone cortical layer & Thinner & Thicker \\
\hline SIJ surface area & Lesser & Greater \\
\hline Pelvis & Wider, shorter & Narrower, taller \\
\hline Sciatic notch & Wider & Narrower \\
\hline Acetabula & Wider & Narrower \\
\hline Pubic angle & Larger $\left(90^{\circ}\right.$ to $\left.100^{\circ}\right)$ & Smaller $\left(50^{\circ}\right.$ to $\left.80^{\circ}\right)$ \\
\hline $\begin{array}{l}\text { Interosseous sacroiliac } \\
\text { ligament }\end{array}$ & Larger & Smaller \\
\hline $\begin{array}{l}\text { Anterior sacroiliac } \\
\text { ligaments }\end{array}$ & Smaller & Larger \\
\hline $\begin{array}{l}\text { Posterior sacroiliac } \\
\text { ligaments }\end{array}$ & Smaller & Larger \\
\hline
\end{tabular}

than women, which consequentially allows men to withstand greater loads. While the average auricular surface area for women has been reported to range from 10.7 to $14.2 \mathrm{~cm}^{2},{ }^{12,38}$ with an upper limit of 18 $\mathrm{cm}^{2}{ }^{19}$ this ligamentous area for men is approximately $22.3 \mathrm{~cm}^{2} .^{12}$ Another reason that men can withstand greater load may be that men possess significantly higher lumbar isometric strength, almost twice that of women, thus requiring more significant load transfers through the SIJs. ${ }^{39,40}$

Joukar et $\mathrm{al}^{5}$ studied the biomechanical differences between male and female SIJs using finite element analysis (Figure 6). The female SIJ had higher mobility, stresses, loads, and pelvis ligament strains compared to the male SIJ. This could be a possible reason for the higher incidence of SIJ pain and the pelvic stress fracture in women. 

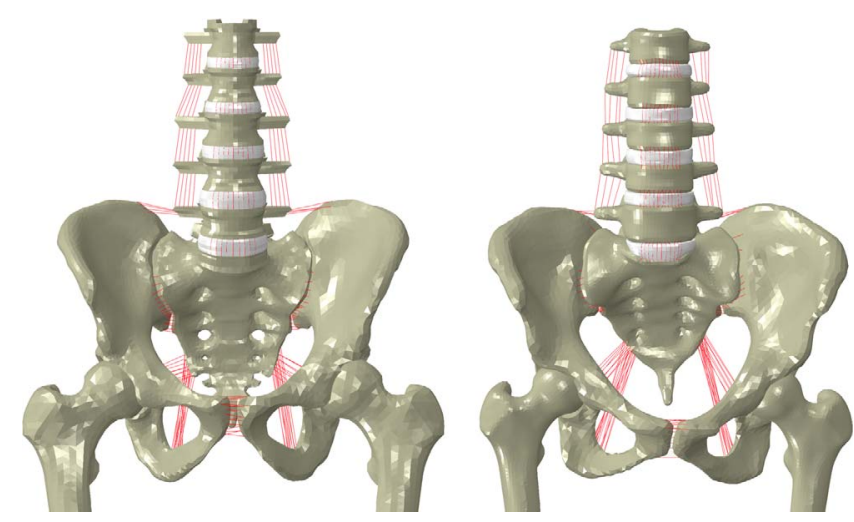

Figure 6. Finite element models of male (left) and female (right) of spine, pelvis, and femur.

The male and female SIJ angular ROMs are different, with the maximum ROM of $1.2^{\circ}$ (men) and $2.8^{\circ}$ (women).

Another significant influence on the development of particular SIJ form is the center of gravity, which is located in different positions for men and women. Compared to men, who have a more ventral center of gravity, the center of gravity in women commonly passes in front of or through the SIJ. ${ }^{41,42}$ This difference implies that men would have a greater lever arm than women, accounting for the higher loads on the joints and stronger SIJs in men. ${ }^{21}$ This characteristic also may explain why men have more restricted mobility, as the average movement for men is approximately $40 \%$ less than that of women. ${ }^{21,43,44}$

The increased mobility of the SIJ in women may be due to individual anatomical correlations. Two features that allow for higher mobility in women are the less pronounced curvature of the SIJ surfaces and a greater pubic angle compared to men. While men typically have a pubic angle of between $48^{\circ}$ and $81^{\circ}$, women have an average pubic angle of $82^{\circ}\left(64^{\circ}\right.$ to $\left.100^{\circ}\right){ }^{45}$ A possible reason for these differences is the facilitation of parturition in women, which involves the influence of hormones such as relaxin. ${ }^{2,3,46}$ Under the effect of relaxin, relative symphysiolysis appears to occur, and both of these factors loosen the SIJ fibrous apparatus, thus increasing mobility. ${ }^{21}$ While these unique aspects of the SIJ provide women with the necessary ability to give birth, they also may predispose women to a greater risk of pelvic pain. ${ }^{47-50}$ One factor that plays a major role in determining the severity of this predisposition involves the laxity of the female SIJs during pregnancy. According to a study by Damen et al, ${ }^{51}$ women who experience asymmetric laxity of the SIJs during pregnancy are 3 times more likely to develop moderate to severe pelvic girdle pain than women who experience symmetric laxity. As the particular form of the SIJ differs immensely between men and women, it becomes rather clear that women are more likely to develop pelvic girdle pain, and are therefore at greater risk of experiencing LBP.

\section{Summary}

Sexual dimorphism exists in the pelvis with the female sacrum being wider, more uneven, less curved, and more backward tilted. Men tend to have a relatively long and narrow pelvis, with a longer and more conical pelvic cavity than that of women. Briefly, women have a higher ROMs, thicker sacral cartilage, thinner iliac cortical bone, smaller SIJ surface area, larger interosseous sacroiliac ligaments, and smaller anterior and posterior sacroiliac ligaments. Moreover, women have higher mobility, greater stresses, greater loads, and more pelvis ligament strains compared to men. Another big difference is the influence of hormones such as relaxin in women, which increases the mobility of the SIJ by providing ligament laxity for giving birth. In summary, women are more prone to the incidences of SIJ and pelvic pain due to high mobility.

\section{CAUSES OF SIJ PAIN}

From an anatomical perspective, pathologic changes and injuries specific to different SIJ structures can result in SIJ pain. These changes include, but are not limited to, capsular and ligamentous tension, hypo- or hypermobility, extraneous compression or shearing forces, micro- or macro-fractures, soft tissue injury, and inflammation. $^{2}$ The mechanism of SIJ injury primarily is due to a combination of axial loading and abrupt rotation. ${ }^{52}$ SIJ pain may also be due to injuries sustained from falling directly on the buttocks, and collisions during sports or driving. Prior medical procedures may also play a role in SIJ pain and dysfunction.

Several studies have reported that prior lumbar fusion can directly increase angular motion and stresses across the patient's SIJ, and these parameters are strongly correlated to the specific lumbar levels (one or more) fused. ${ }^{53}$ It is well known that the surgical arthrodesis at one level causes degeneration of an adjacent segment-adjacent segment disease/disorder. ${ }^{53-56}$ 
Table 4. Causes of intra-articular and extra-articular SIJ pain. ${ }^{65}$

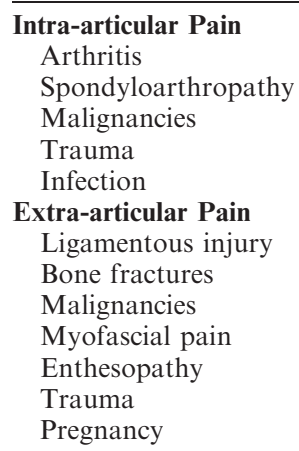

Limb length discrepancy (LLD), is another potential contributor to SIJ pain. Several authors have reported the correlation between LLD, LBP, and SIJ dysfunction. ${ }^{2,57-59}$ Due to the length discrepancy, the mechanical alignment of the SIJs become increasingly imbalanced, resulting in uneven load distribution across both SIJs. ${ }^{2,57,59}$

Kiapour et $\mathrm{al}^{60}$ quantified the changes in load distribution through the SIJ as a result of LLDs of 1,2 , and $3 \mathrm{~cm}$. The peak loads and stresses on both legs were higher than that of the intact or normal model, with a greater magnitude consistently occurring on the longer-leg side. Furthermore, as the length discrepancies increased from 1 to $3 \mathrm{~cm}$, the stresses across the SIJ increased accordingly.

Apart from injuries, prior lumbar fusion, and LLD, several other factors contribute to the gradual development of SIJ pain. These include joint infection, spondylo-arthropathies such as ankylosing spondylitis, inflammatory bowel disease, ${ }^{2}$ gait abnormalities, ${ }^{61}$ scoliosis, ${ }^{62}$ and excessive exercise. ${ }^{63}$ Regardless of the cause, the association of pain with SIJ dysfunction is rather consistent. Table 4 summarizes the causes of intra-articular and extraarticular SIJ pain.

During pregnancy, many hormonal and biomechanical changes occur, contributing to ligament laxity. One of the leading musculoskeletal changes is the increase in the mass of uterus and breasts that cause anterior displacement of the center of gravity. This effect heightens joint loads (eg, increases hip joint anterior torque by 8 times) and is aggravated by the laxity of other ligaments and other joints, which may contribute to pain and risk of injury. ${ }^{64}$

\section{OVERALL SUMMARY}

The SIJs are complex joints sitting in between the sacrum and iliac bone on either side of the pelvis.
The joints play a vital role in transmitting upper body loads to lower extremities via the hip joints. The wedging of the sacrum in between pelvic bones, irregular and rough surface of the joint itself, and tight banding due to ligaments and pelvic floor muscles (levator ani and coccygeus muscles) make the SIJ extremely stable. SIJ pain can be due to, but is not limited to, capsular and ligamentous tension, hypo- or hypermobility, extraneous compression or shearing forces, and host of other factors. Other sources of pain are the surgical arthrodesis at one level causing degeneration of an adjacent segment, LLD, and spondylo-arthropathies. There are anatomical differences between the male and female pelvis, including SIJ characteristics. As well as these differences, in women, ligaments become lax during pregnancy. These factors may make women more prone to LBP. To restore quality of life and alleviate LBP due to SIJs, conservative and surgical treatments are available. Part II of the manuscript reviews the mechanics of the devices used in minimal surgical procedures.

\section{REFERENCES}

1. Weksler N, Velan GJ, Semionov M, et al. The role of sacroiliac joint dysfunction in the genesis of low back pain: the obvious is not always right. Arch Orthop Trauma Surg. 2007; 127(10):885-888.

2. Cohen SP. Sacroiliac joint pain: a comprehensive review of anatomy, diagnosis, and treatment. Anesth Analg. 2005; 101(5):1440-1453.

3. Dietrichs E. Anatomy of the pelvic joints - a review. Scand J Rheumatol Suppl. 1991; 88:4-6.

4. McCord DH, Cunningham BW, Shono Y, Myers JJ, McAfee PC. Biomechanical analysis of lumbosacral fixation. Spine (Phila Pa 1976). 1992; 17(8 Suppl):S235-S243.

5. Joukar A, Shah A, Kiapour A, et al. Sex specific sacroiliac joint biomechanics during standing upright: a finite element study. Spine (Phila Pa 1976). 2018; 43(18):E1053-E1060.

6. Lingutla KK, Pollock R, Ahuja S. Sacroiliac joint fusion for low back pain: a systematic review and meta-analysis. Eur Spine J. 2016; 25(6):1924-1931.

7. Sachs D, Capobianco R. One year successful outcomes for novel sacroiliac joint arthrodesis system. Ann Surg Innov Res. 2012; 6(1):13.

8. Schwarzer AC, Aprill CN, Bogduk N. The sacroiliac joint in chronic low back pain. Spine (Phila Pa 1976). 1995; 20(1):31-37.

9. Foley BS, Buschbacher RM. Sacroiliac joint pain: anatomy, biomechanics, diagnosis, and treatment. Am J Phys Med Rehabil. 2006; 85(12):997-1006.

10. Dall BE, Eden SV, Rahl MD. Surgery for the Painful, Dysfunctional Sacroiliac Joint. Cham, Switzerland: Springer International Publishing; 2015.

11. Ombregt L, Bisschop P, Ter Veer HJ, et al. Applied anatomy of the sacroiliac joint. In: Ombregt L, Bisschop P, Ter 
Veer HJ, et al., eds. A System of Orthopedic Medicine. London, England: W.B. Saunders; 1995:694.

12. Miller JA, Schultz AB, Andersson GB. Load-displacement behavior of sacroiliac joints. J Orthop Res. 1987; 5(1):92101 .

13. Solonen KA. The sacroiliac joint in the light of anatomical, roentgenological and clinical studies. Acta Orthop Scand Suppl. 1957; 27:1-127.

14. Snijders CJ, Vleeming A, Stoeckart R. Transfer of lumbosacral load to iliac bones and legs. Part 1: biomechanics of self-bracing of the sacroiliac joints and its significance for treatment and exercise. Clin Biomech (Bristol, Avon). 1993; 8(6):285-294.

15. Pel JJ, Spoor CW, Pool-Goudzwaard AL, Hoek van Dijke GA, Snijders CJ. Biomechanical analysis of reducing sacroiliac joint shear load by optimization of pelvic muscle and ligament forces. Ann Biomed Eng. 2008; 36(3):415-424.

16. Pool-Goudzwaard A, Hoek van Dijke G, Mulder P, Spoor C, Snijders C, Stoeckart R. The iliolumbar ligament: its influence on stability of the sacroiliac joint. Clin Biomech (Bristol, Avon). 2003; 18(2):99-105.

17. Yamamoto I, Panjabi MM, Oxland TR, Crisco JJ. The role of the iliolumbar ligament in the lumbosacral junction. Spine (Phila Pa 1976). 1990; 15(11):1138-1141.

18. Vrahas M, Hern TC, Diangelo D, Kellam J, Tile M. Ligamentous contributions to pelvic stability. Orthopedics. 1995; 18(3):271-274.

19. Sashin D. A critical analysis of the anatomy and pathological changes of the sacroiliac joints. JBJS. 1930; 12(4):891-910.

20. Eichenseer PH, Sybert DR, Cotton JR. A finite element analysis of sacroiliac joint ligaments in response to different loading conditions. Spine (Phila Pa 1976). 2011; 36(22):E1446E1452.

21. Vleeming A, Schuenke MD, Masi AT, Carreiro JE, Danneels L, Willard FH. The sacroiliac joint: an overview of its anatomy, function and potential clinical implications. $J$ Anat. 2012; 221(6):537-567.

22. Wang M, Dumas GA. Mechanical behavior of the female sacroiliac joint and influence of the anterior and posterior sacroiliac ligaments under sagittal loads. Clin Biomech (Bristol, Avon). 1998; 13(4-5):293-299.

23. Hammer N, Steinke H, Lingslebe U, et al. Ligamentous influence in pelvic load distribution. Spine J. 2013; 13(10):13211330 .

24. Dujardin FH, Roussignol X, Hossenbaccus M, Thomine JM. Experimental study of the sacroiliac joint micromotion in pelvic disruption. J Orthop Trauma. 2002; 16(2):99-103.

25. Buyruk HM, Stam HJ, Snijders CJ, Vleeming A, Lameris JS, Holland WP. The use of color Doppler imaging for the assessment of sacroiliac joint stiffness: a study on embalmed human pelvises. Eur J Radiol. 1995; 21(2):112-116.

26. Rothkotter HJ, Berner W. Failure load and displacement of the human sacroiliac joint under in vitro loading. Arch Orthop Trauma Surg. 1988; 107(5):283-287.

27. Berber O, Amis AA, Day AC. Biomechanical testing of a concept of posterior pelvic reconstruction in rotationally and vertically unstable fractures. J Bone Joint Surg Br. 2011; 93(2):237-244.

28. Sturesson B, Selvik G, Uden A. Movements of the sacroiliac joints. A roentgen stereophotogrammetric analysis. Spine (Phila Pa 1976). 1989; 14(2):162-165.

29. Vlaanderen E, Conza NE, Snijders CJ, Bouakaz A, De Jong N. Low back pain, the stiffness of the sacroiliac joint: a new method using ultrasound. Ultrasound Med Biol. 2005; 31(1):39-44.

30. Zheng N, Watson LG, Yong-Hing K. Biomechanical modelling of the human sacroiliac joint. Med Biol Eng Comput. 1997; 35(2):77-82.

31. Walker JM. The sacroiliac joint: a critical review. Phys Ther. 1992; 72(12):903-916.

32. White AA, Panjabi MM. Clinical Biomechanics of the Spine. 2nd ed. Philadelphia: JB Lippincott; 1990.

33. Vleeming A, Van Wingerden JP, Dijkstra PF, Stoeckart R, Snijders CJ, Stijnen T. Mobility in the sacroiliac joints in the elderly: a kinematic and radiological study. Clin Biomech (Bristol, Avon). 1992; 7(3):170-176.

34. Vleeming A, Van Wingerden JP, Snijders CJ, Stoeckart R, Stijnen T. Load application to the sacrotuberous ligament; influences on sacroiliac joint mechanics. Clin Biomech. 1989; 4(4):204-209.

35. Brunner C, Kissling R, Jacob HA. The effects of morphology and histopathologic findings on the mobility of the sacroiliac joint. Spine (Phila Pa 1976). 1991; 16(9):1111-1117.

36. Jacob HA, Kissling RO. The mobility of the sacroiliac joints in healthy volunteers between 20 and 50 years of age. Clin Biomech (Bristol, Avon). 1995; 10(7):352-361.

37. Tortora GJ, Derrickson BH. Introduction to the Human Body: The Essentials of Anatomy and Physiology. 7th ed. New York, NY: Wiley; 2006.

38. Ebraheim NA, Biyani A. Percutaneous computed tomographic stabilization of the pathologic sacroiliac joint. Clin Orthop Relat Res. 2003; 408:252-255.

39. Graves JE, Pollock ML, Carpenter DM, et al. Quantitative assessment of full range-of-motion isometric lumbar extension strength. Spine (Phila Pa 1976). 1990; 15(4):289-294.

40. Masi AT. Do sex hormones play a role in ankylosing spondylitis? Rheum Dis Clin North Am. 1992; 18(1):153-176.

41. Bellamy N, Park W, Rooney PJ. What do we know about the sacroiliac joint? Semin Arthritis Rheum. 1983; 12(3):282-313.

42. Tichauer ER, Miller M, Nathan IM. Lordosimetry: a new technique for the measurement of postural response to materials handling. Am Ind Hyg Assoc J. 1973; 34(1):1-12.

43. Sturesson B, Uden A, Vleeming A. A radiostereometric analysis of movements of the sacroiliac joints during the standing hip flexion test. Spine (Phila Pa 1976). 2000; 25(3):364-368.

44. Sturesson B, Uden A, Vleeming A. A radiostereometric analysis of the movements of the sacroiliac joints in the reciprocal straddle position. Spine (Phila Pa 1976). 2000; 25(2):214-217.

45. Karakas HM, Harma A, Alicioglu B. The subpubic angle in sex determination: anthropometric measurements and analyses on Anatolian Caucasians using multidetector computed tomography datasets. J Forensic Leg Med. 2013; 20(8):1004 1009.

46. Ross J. Is the sacroiliac joint mobile and how should it be treated? Br J Sports Med. 2000; 34(3):226.

47. Borell U, Fernstrom I. The movements at the sacro-iliac 
joints and their importance to changes in the pelvic dimensions during parturition. Acta Obstet Gynecol Scand. 1957; 36(1):4257.

48. Brooke R. The sacro-iliac joint. J Anat. 1924; 58(Pt 4):299-305.

49. Chamberlain WE. The symphysis pubis in the roentgen examination of the sacroiliac joint. Am J Roentgenol Radium Ther. 1930; 24(6):621-625.

50. Hisaw FL. The influence of the ovary on the resorption of the pubic bones of the pocket gopher, Geomys bursarius. $J$ Exp Zool. 1925; 42(4):411-441.

51. Damen L, Buyruk HM, Guler-Uysal F, Lotgering FK, Snijders CJ, Stam HJ. Pelvic pain during pregnancy is associated with asymmetric laxity of the sacroiliac joints. Acta Obstet Gynecol Scand. 2001; 80(11):1019-1024.

52. Dreyfuss PC, Cole AJ, Pauza K. Sacroiliac joint injection techniques. Phys Med Rehabil Clin North Am. 1995; 6(4):785813.

53. Ivanov AA, Kiapour A, Ebraheim NA, Goel V. Lumbar fusion leads to increases in angular motion and stress across sacroiliac joint: a finite element study. Spine (Phila Pa 1976). 2009; 34(5):E162-E169.

54. Ha KY, Lee JS, Kim KW. Degeneration of sacroiliac joint after instrumented lumbar or lumbosacral fusion: a prospective cohort study over five-year follow-up. Spine (Phila Pa 1976). 2008; 33(11):1192-1198.

55. Hilibrand AS, Robbins M. Adjacent segment degeneration and adjacent segment disease: the consequences of spinal fusion? Spine J. 2004; 4(6 Suppl):190S-194S.

56. Park P, Garton HJ, Gala VC, Hoff JT, McGillicuddy JE. Adjacent segment disease after lumbar or lumbosacral fusion: review of the literature. Spine (Phila Pa 1976). 2004; 29(17):1938-1944.

57. Golightly YM, Tate JJ, Burns CB, Gross MT. Changes in pain and disability secondary to shoe lift intervention in subjects with limb length inequality and chronic low back pain: a preliminary report. J Orthop Sports Phys Ther. 2007; 37(7):380-388.

58. Schuit D, McPoil TG, Mulesa P. Incidence of sacroiliac joint malalignment in leg length discrepancies. $J$ Am Podiatr Med Assoc. 1989; 79(8):380-383.

59. Winter RB, Pinto WC. Pelvic obliquity. Its causes and its treatment. Spine (Phila Pa 1976). 1986; 11(3):225-234.
60. Kiapour A, Abdelgawad AA, Goel VK, Souccar A, Terai T, Ebraheim NA. Relationship between limb length discrepancy and load distribution across the sacroiliac joint - a finite element study. J Orthop Res. 2012; 30(10):1577-1580.

61. Herzog W, Conway PJ. Gait analysis of sacroiliac joint patients. J Manipulative Physiol Ther. 1994; 17(2):124-127.

62. Schoenberger M, Hellmich K. Sacroiliac dislocation and scoliosis. Hippokrates. 1964; 35:476-479.

63. Marymont JV, Lynch MA, Henning CE. Exerciserelated stress reaction of the sacroiliac joint. An unusual cause of low back pain in athletes. Am J Sports Med. 1986; 14(4):320323.

64. Fitzgerald CM, Segal N. Musculoskeletal health in pregnancy and postpartum. Cham, Switzerland: Springer International Publishing; 2015.

65. Holmes SL, Cohen SP, Cullen MFL, Kenny CD, Wain HJ, Davis SA. Sacroiliac joint pain. In: Pain Medicine: An Interdisciplinary Case-Based Approach. Oxford, Englad: Oxford University Press; 2015:160-182.

Disclosures and COl: Work supported in part by the National Science Foundation Industry/ University Cooperative Research Center, University of California at San Francisco and University of Toledo and research grants from SI-Bone, Inc. Santa Clara, California.

Corresponding Author: Vijay K. Goel, PhD, Departments of Bioengineering and Orthopaedic Surgery, Colleges of Engineering and Medicine, University of Toledo, Toledo, $\mathrm{OH}$ 43606. Phone: (419) 530-8035; Fax: (419) 530-8076; Email: Vijay. Goel@utoledo.edu.

Published 10 February 2020

This manuscript is generously published free of charge by ISASS, the International Society for the Advancement of Spine Surgery. Copyright (C) 2020 ISASS. To see more or order reprints or permissions, see http://ijssurgery.com. 